\title{
Second Harmonic Generation in Some Donor-Acceptor Substituted Chalcone Derivatives
}

\author{
P. S. Patil ${ }^{1 *}$, V. M. Bhumannavar ${ }^{1,2}$, M. S. Bannur ${ }^{1,3}$, Harish N. Kulkarni ${ }^{1,4}$, G. Bhagavannarayana ${ }^{5}$ \\ ${ }^{1}$ Department of Physics, K.L.E. Institute of Technology, Hubli, India; ${ }^{2}$ Department of Physics, P. C. Jobin Science College, Hubli, \\ India; ${ }^{3}$ Department of Physics, K.L.S. Vishwanathrao Deshpande Rural Institute of Technology, Hliyal, India; ${ }^{4}$ Department of Phys- \\ ics, S.T.J. Institute of Technology, Ranebennur, India; ${ }^{5}$ Materials Characterization Division, National Physical Laboratory, New \\ Delhi, India. \\ Email: "pspatilcrystal@gmail.com
}

Received May $23^{\text {rd }}, 2013$; revised June $23^{\text {rd }}, 2013$; accepted July $1^{\text {st }}, 2013$

Copyright (C) 2013 P. S. Patil et al. This is an open access article distributed under the Creative Commons Attribution License, which permits unrestricted use, distribution, and reproduction in any medium, provided the original work is properly cited.

\begin{abstract}
A series of five chalcone derivatives with different substituents in para and meta posions have been synthesized, and single crystals were successfully grown in aceton solution by slow evaporation solution growth technique (SESGT). Single crystal X-ray studies revealed that all the crystals crystallized in noncentrosymmetric space group with their molecular dipoles perfectly aligned in a direction-favorable for large nonlinear optical effects. Kurtz powder tests revealed that all five materials have second-harmonic-generating properties with maximum efficiencies of approximately 14 times that of urea standard. UV-vis-NIR spectroscopy and thermogravimetric analyses are also presented for all of the reported materials. Among the five chalcones, high quality single crystals of 4-Methoxy-4'-chlorochalcone were grown by SESGT, and its crystalline perection were studied by using a high resolution X-ray diffractometry (HRXRD).
\end{abstract}

Keywords: Nonlinear Optical Materials; Organic Compounds; Crystal Growth; Second Harmonic Generation; TGA/DTA

\section{Introduction}

The realization of suitable organic NLO material for use in devices is by no means a simple task as material must have unique properties at both the microscopic and macroscopic level. Microscopic properties required for organic NLO material include high first order hyperpolarizability $(\beta)$, noncentrosymmetric structure, and wide transparence wavelength range. Requirements on the macroscopic level include a noncentrosymmetric spatial arrangement of charge transfer chromophores present in organic NLO material, or bulk order, as well as excellent photo, thermal, and thermodynamic stability, while also being soluble in common solvents allowing simple processing [1-3]. Development of novel molecular and crystal design techniques for assembling such materials is of great current interest.

From the viewpoint of applications to optical devices, organic materials have several distinguishing features; processability, cost effectiveness, high damage threshold,

\footnotetext{
${ }^{*}$ Corresponding author.
}

large nonlinearity, and the ease with which large crystals of high optical quality can be grown and fabricated into desired shapes [1-3]. In recent years, as an interesting type of nonlinear optical materials, chalcone and its derivatives have recently received extensively attention due to their high tendency to crystallize in noncentrosymmetric structure, excellent second harmonic generation conversion efficiency, and good optical limiting behavior with nanosecond laser pulse at $532 \mathrm{~nm}$ wavelength [4-7]. The microscopic origin of nonlinearity in this molecular NLO material is due to the presence of delocalized $\pi$ electron systems connecting donor and acceptor groups which enhance the necessary asymmetric polarizability.

Herein, we report the synthesis, structures, and characterization of a series of five chalcone derivatives, obtained by carefully modifying the structure with various para and meta substitutents, expecting new molecules with high second-order optical nonlinearities. Two of the five chalcones we synthesized have high SHG intensities compared to urea. This indicates that the p-substituent on the phenyl ring plays an important role in the crystal 
structure and SHG activity of organic materials. The present study forms a basis for optimizing chalcone derivatives structures to improve their second-order nonlinear optical properties and therma stability.

\section{Experimental}

\subsection{Synthesis of Chalcones: Claisen-Schmidt Reaction}

All aldehydes and acetophenones were purchased from Sigma-Aldrich Chemical Company (India) with a stated purity of greater than $98 \%$, and they were used as such without further purification. The five derivatives of chalcone substituted with donor-acceptor substituents (Table 1) were prepared by Claisen-Schmidt condensation reaction [8] (Scheme 1). The solvents (ethanol and acetone) used were either of analytical grade or bulk solvents distilled before use. The crude products were recrystallized with acetone. For example, in case of 4-Methoxy-4'chlorochalcone, 4-methoxybenzaldehyde $(0.01 \mathrm{~mol})$ and 4 '-chloroacetophenone $(0.01 \mathrm{~mol})$ were stirred in $60 \mathrm{ml}$ of ethanol at room temperature. Ten milliliters of $10 \%$ of $\mathrm{NaOH}$ aqueous solution was added and the mixture was stirred for 2 hours. The reaction mixture was chilled in ice cold water for 10 - 15 minutes, filtered, washed with water, dried and the crude product recrystallized twice from acetone.

\subsection{Solubility and Crystal Growth}

Growth of organic crystals having well developed faces and good optical quality mainly depends on the selection of suitable solvents. Solvents offering moderate solubility-temperature gradient for a material and yielding prismatic growth habit will be considered as suitable solvents for growing crystal of that material. All the five chalcones are insoluble in water, and soluble in acetone, N,N-dimethylformamide (DMF), chloroform, etc. The solubility of MCC was determined using aceton, since acetone is found to be a suitable solvent to grow considerable size crystals. Recrystallized compound was dissolved in acetone and the solution was maintained at $30^{\circ} \mathrm{C}$ in a constant temperature bath and stirred continu ously to ensure homogenization of the solution. On reaching the saturation, the amount of the MCC in the solution was analyzed gravimetrically. The same procedure was repeated for the temperatures $35^{\circ} \mathrm{C}, 40^{\circ} \mathrm{C}, 45^{\circ} \mathrm{C}$ and $50^{\circ} \mathrm{C}$ and results are shown in Figure 1. The MCC exhibits good solubility and a positive solubility temperature gradient in acetone.

Single crystals suitable for X-ray diffraction studies of all the compounds were obtained from slow evaporation of their acetone solutions at room temperature. Among the five chalcones, large crystals of MCC of dimensions $22 \times 2 \times 3 \mathrm{~mm}$ were grown at room temperature. The crystals were found to be needle and they grew as thick

Table 1. List of synthesized chalcones.

\begin{tabular}{|c|c|c|c|c|}
\hline Sl. No. & Abbreviation & Chemical Name & Molecular Structure & MF and $\mathrm{FW}^{*}$ \\
\hline 1. & $\mathrm{MCC}$ & $\begin{array}{c}\text { 3-(4-methoxyphenyl) } \\
\text {-1-(4-chlorophenyl)prop-2-en-1-o } \\
\text { ne }\end{array}$ & & $\begin{array}{c}\mathrm{C}_{16} \mathrm{H}_{13} \mathrm{ClO}_{2} \\
\mathrm{Mr}=272.71\end{array}$ \\
\hline 2. & $3 \mathrm{MMC}$ & $\begin{array}{c}\text { 3-(3-methoxyphenyl) } \\
\text {-1-(4-methoxy } \\
\text { phenyl)prop-2-en-1-one }\end{array}$ & & $\begin{array}{c}\mathrm{C}_{17} \mathrm{H}_{16} \mathrm{O}_{3} \\
\mathrm{M}_{\mathrm{r}}=268.30\end{array}$ \\
\hline 3. & $\mathrm{ECC}$ & $\begin{array}{c}\text { 3-(4-ethoxyphenyl) } \\
\text {-1-(4-chlorophenyl)prop-2-en } \\
\text {-1-one }\end{array}$ & & $\begin{array}{c}\mathrm{C}_{17} \mathrm{H}_{15} \mathrm{ClO}_{2} \\
\mathrm{M}_{\mathrm{r}}=286.74\end{array}$ \\
\hline 4. & $\mathrm{EBC}$ & $\begin{array}{c}\text { 3-(4-ethoxyphenyl) } \\
\text {-1-(4-bro- } \\
\text { mophenyl)prop-2-en-1-one }\end{array}$ & & $\begin{array}{c}\mathrm{C}_{17} \mathrm{H}_{15} \mathrm{BrO}_{2} \\
\mathrm{M}_{\mathrm{r}}=331.19\end{array}$ \\
\hline 5. & E3BC & $\begin{array}{c}\text { 3-(4-ethoxyphenyl) } \\
\text {-1-(3-bro- } \\
\text { mophenyl)prop-2-en-1-one }\end{array}$ & & $\begin{array}{l}\mathrm{C}_{17} \mathrm{H}_{15} \mathrm{BrO}_{2} \\
\mathrm{M}_{\mathrm{r}}=331.19\end{array}$ \\
\hline
\end{tabular}

*Molecular Formula and Formula Weight. 
<smiles>[R2]c1ccc(/C=C/C(=O)c2ccc([R2])cc2)cc1</smiles>

Scheme 1. Synthesis of chalcones. (a): $\mathrm{R}_{1}=4-\mathrm{OCH}_{3}, \mathrm{R}_{2}=$ 4-Cl; (b): $\mathrm{R}_{1}=3-\mathrm{OCH}_{3}, \mathrm{R}_{2}=4-\mathrm{OCH}_{3}$; (c): $\mathrm{R}_{1}=4-\mathrm{OC}_{2} \mathrm{H}_{5}, \mathrm{R}_{2}$ = 4-Cl; (d): $\mathrm{R}_{1}=4-\mathrm{OC}_{2} \mathrm{H}_{5}, \mathrm{R}_{2}=4-\mathrm{Br} ;(\mathrm{e}): \mathrm{R}_{1}=4-\mathrm{OC}_{2} \mathrm{H}_{5}, \mathrm{R}_{2}$ $=3-\mathrm{Br}$.

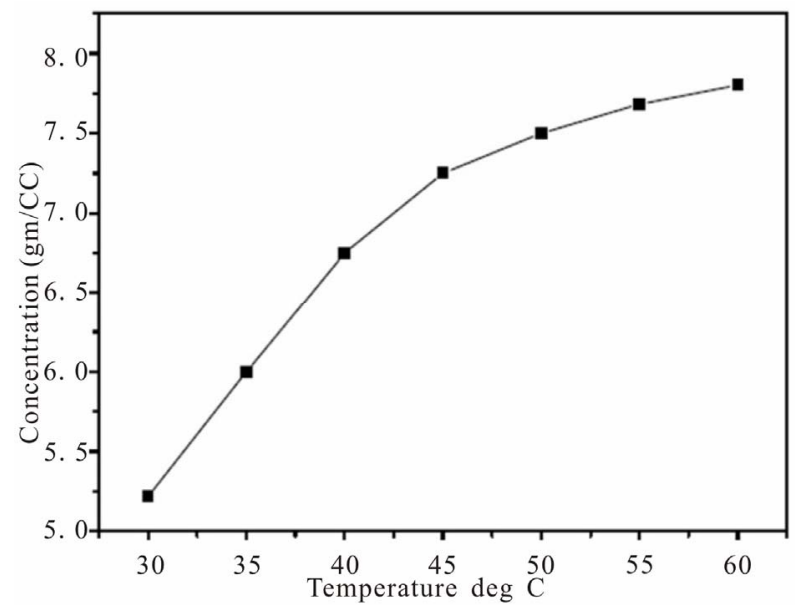

Figure 1. Solubility curve of MCC.

needles (Figure 2).

\subsection{Characterisation}

The single crystal X-ray diffraction data was collected on a Bruker SMART APEX2 CCD area detector diffractometer.The radiation used was graphite monochromatic $M o K \alpha_{1}$ radiation. To investigate the thermal stability of the chalcones, differential thermal analysis (DTA) and thermogravimetric analysis (TGA) of the chalcones were carried out using the Shimadzu DT-40 simultaneous DTA/TGA analyzer with a heating rate of $10^{\circ} \mathrm{C} / \mathrm{min}$ under the nitrogen atmosphere. For the optical transmission study, the UV-VIS-NIR absorption spectrums of the samples in dilute acetone solution were recorded using a SHIMADZU UV-1061 spectrophotometer in the wavelength range of $300-1100 \mathrm{~nm}$. The SHG efficiency of the microcrystalline powder of the samples was examined by the powder reflection technique of Kurtz and Perry [9]. Laser beam from a Q-switched Nd: YAG pulsed laser $(1064 \mathrm{~nm}, 8 \mathrm{~ns}, 10 \mathrm{~Hz})$ was used. The $95 \%$

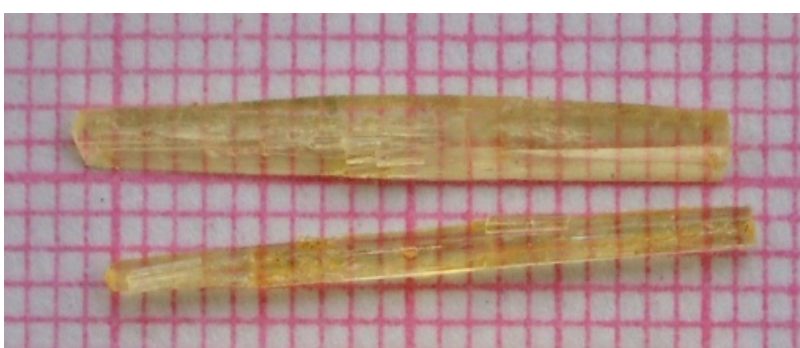

Figure 2. Photograph of as grown MCC crystals.

fundamental was focused on the polycrystalline sample capillary tube, while the $5 \%$ of the intensity of the fundamental beam was used as a reference beam to normalize the fluctuations of the incident laser. The second harmonic $(\mathrm{SH})$ radiation at $532 \mathrm{~nm}$ obtained at the output was filtered using an $\mathrm{SH}$ separator to remove the fundamental input radiation. SHG was detected by RCA-931A photomultiplier tube (PMT), which is connected to 100 $\mathrm{MHz}$ digital storage oscilloscope (DSO). A sample of urea was used as a reference material.

To reveal the crystalline perfection of the grown MCC crystals, a multicrystal X-ray diffrcatometer (MCD) developed at NPL has been used to record high-resolution diffraction curves (DCs) [10]. In this system a fine focus $(0.4 \times 8 \mathrm{~mm} ; 2 \mathrm{~kW}$ Mo) X-ray source energized by a well-stabilized Philips X-ray generator (PW 1743) was employed. The well-collimated and monochromated Mo$\mathrm{K}_{1}$ beam obtained from the three monochromator $\mathrm{Si}$ crystals set in dispersive $(+,-,-)$ configuration has been used as the exploring X-ray beam. This arrangement improves the spectral purity $(\Delta \lambda / \lambda<<10-5)$ of the MoK $\alpha_{1}$ beam. The divergence of the exploring beam in the horizontal plane (plane of diffraction) was estimated to be $<<$ 3 arc sec. The specimen crystal is aligned in the $(+,-,-$, + ) configuration. Due to dispersive configuration, though the lattice constant of the monochromator crystal(s) and the specimen are different, the unwanted dispersion broadening in the diffraction curve of the specimen crystal is insignificant. The specimen can be rotated about a vertical axis, which is perpendicular to the plane of diffracttion, with minimum angular interval of $0.5 \mathrm{arc} \mathrm{sec}$. The diffracted intensity is measured by using a scintillation counter and is mounted with its axis along a radial arm of the turntable. The rocking or diffraction curves were recorded by changing the glancing angle (angle between the incident X-ray beam and the surface of the specimen) around the Bragg diffraction peak position $\theta_{\mathrm{B}}$ starting from a suitable arbitrary glancing angle (denoted as zero). The detector was kept at the same angular position $2 \theta_{\mathrm{B}}$ with wide opening for its slit, the so-called $\omega$ scan. Before recording the diffraction curve to remove the noncrystallized solute atoms remained on the surface of the crystal and also to ensure the surface planarity, the specimen was first lapped and chemically etched in a non 
preferential etchant of water and acetone mixture in 1:2 volume ratio. This process also ensures to remove surface layers, which may some times form for e.g. a complexing epilayer may form on the surface of the crystal due to organic additives [11].

\section{Results and Discussion}

\subsection{Single-Crystal XRD}

Although the preliminary focus of this study is on the molecular quadratic NLO responses of the new chalcone derivatives, the investigation of their bulk NLO properties is obviously of great importance. However, the possibilities for such studies are clearly somewhat limited by our ability to force the compounds to crystallize in a favorable noncentrosymmetric structure. We have obtained single crystal structures for all the compounds and their unit cell parameters, crystal systems and space groups are summaried in Table 2. The detail structural analysis and results can be found in our earlier publications [12-16]. All compounds studied crystallize noncentrosymmetrically, and thus satisfies the requirement for the SHG activity in the crystal.

\subsection{Structure and Second Harmonic Generation Efficiency Relationship}

Chalcones are cross-conjugated molecules, and the carbonyl group in these systems breaks the conjugation system into two independent parts to have a two dimensional $\beta$ character. In the molecular structure of MCC, $3 \mathrm{MMC}, \mathrm{ECC}, \mathrm{EBC}$ and $\mathrm{E} 3 \mathrm{BC}$, the para position of benzoyl ring and phenylene ring consist of $\mathrm{Cl}, \mathrm{OCH}_{3}, \mathrm{Br}$ and $\mathrm{OCH}_{3}, \mathrm{OC}_{2} \mathrm{H}_{5}$ atom repectively. All the substituents $\left(\mathrm{OC}_{2} \mathrm{H}_{5}, \mathrm{OCH}_{3}, \mathrm{Br}\right.$, and $\left.\mathrm{Cl}\right)$ are electron donating groups (the electron donating strength: $\mathrm{OC}_{2} \mathrm{H}_{5}>\mathrm{OCH}_{3}>\mathrm{Br}>$ $\mathrm{Cl})$. All the chalcones containing electron donating groups at the ends and an electron acceptor carbonyl $(\mathrm{C}=$ O) group at the middle forms a donor- $\pi$-acceptor- $\pi$-donor (D- $\pi-A-\pi-D)$ system, where charge transfer takes place from the donor ends to the acceptor at the middle of the molecule. The charge transfer to the carbonyl group is more effective from the donor attached to the phenylene group, rather than the benzoyl group. The shape of the chalcone derivatives can be considered as lambda shape ( $\lambda$-shape); which helps to align the molecule in parallel head to tail alignment in the crystal packing [3]. Such molecular alignment usually exhibits high SHG efficien-

Table 2. Crystal data, SHG efficiencies, cutoff wavelengths and melting pints of five chalcone derivatives.

\begin{tabular}{|c|c|c|c|c|c|c|c|}
\hline Sl.No. & Code & Crystal data & $\begin{array}{l}\text { Hydrogen bond } \\
\text { interactions }\end{array}$ & $\begin{array}{l}\text { Dihedral } \\
\text { Angle }\end{array}$ & PSHGE $^{*}$ (U) & $\lambda_{\text {cut-off }}(\mathbf{n m})$ & $\operatorname{M.P}\left({ }^{\circ} \mathrm{C}\right)$ \\
\hline 1 & $\mathrm{MCC}$ & $\begin{array}{c}\text { Orthorhombic, } \\
\text { Pna } 21 \\
\mathrm{a}=12.8179(4) \AA \\
\mathrm{b}=25.5550(6) \AA \\
\mathrm{c}=3.9175(1) \AA \\
\mathrm{Z}=4\end{array}$ & C-H...O & $21.8(6)^{\circ}$ & 2 & 424 & 113.09 \\
\hline 2. & $3 \mathrm{MMC}$ & $\begin{array}{c}\text { Monoclinic, } \mathrm{P} 2_{1} \\
\mathrm{a}=7.7629(3) \AA \\
\mathrm{b}=5.5537(2) \AA \\
\mathrm{c}=15.7450(6) \AA \\
\beta=90.828(2)^{\circ} \\
\mathrm{Z}=2\end{array}$ & $\begin{array}{l}\text { C-H... } \\
\text { C-H... }\end{array}$ & $10.05(9)^{\circ}$ & 10.30 & 400 & 088.18 \\
\hline 3. & ECC & $\begin{array}{c}\text { Monoclinic, } \mathrm{P} 2_{1} \\
\mathrm{a}=3.9479(1) \AA \\
\mathrm{b}=10.1234(3) \AA \\
\mathrm{c}=17.2553(6) \AA \\
\beta=91.823(2)^{\circ} \\
\mathrm{Z}=2\end{array}$ & C-H...O & $8.73(9)^{\circ}$ & 09.00 & 420 & 124.46 \\
\hline 4. & $\mathrm{EBC}$ & $\begin{array}{c}\text { Monoclinic, } \mathrm{P} 2_{1} \\
\mathrm{a}=3.9855(1) \AA \\
\mathrm{b}=10.0681(3) \AA \\
\mathrm{c}=17.5270(4) \AA \\
\beta=92.227(2)^{\circ} \\
\mathrm{Z}=2\end{array}$ & C-H...O & $8.51(19)^{\circ}$ & 14.00 & 410 & 128.08 \\
\hline 5. & E3BC & $\begin{array}{c}\text { Monoclinic, } \mathrm{P} 2_{1}, \\
\mathrm{a}=4.0516(1) \AA, \\
\mathrm{b}=9.6501(2) \AA, \\
\mathrm{c}=17.9120(4) \AA, \\
\beta=92.396(1)^{\circ}, \mathrm{Z}=2\end{array}$ & C-H...O & $10.09(11)^{\circ}$ & 11.00 & 405 & 127.93 \\
\hline
\end{tabular}

*Powder second harmonic generation efficiency. 
cy [3]. The presence of strong electron donating groups, the parallel head to tail alignment, inter and intra molecular hydrogen bonds are the reasons to get high SHG efficiency. The one of the parameter which controls the molecular orientation and the stability of the crystal structure are the hydrogen bond interactions [17-18]. For efficient SHG the molecules arranged in parallel or zigzag head-to-tail fashion with molecules interlinked by strong hydrogen bond interactions are essential [19]. The $\mathrm{D}$ (donor)-H... X (acceptor), $\pi \ldots \pi$ type interactions are believed to contribute significantly to the macroscopic NLO properties of organic crystals in the exited state [20]. These hydrogen bond interactions are the virtual roots to extend the molecular charge transfer into supramolecular realm and there by extending the conjugation throughout the interaction length of the crystal. Such an increase in the conjugation via hydrogen bond interacttions leads to the very high SHG efficiency of molecular crystals $[20,21]$. The strength and type of the intermolecular hydrogen bonds also usually matter in NLO materials. The hydrogen bond interactions like D-H...X (where $\mathrm{X}=\mathrm{O}, \mathrm{N}, \mathrm{S} \ldots$ ) contributes less to the conjugation effect. The contribution from C-H... $\pi$ ( $\pi$ is the centre of the benzene ring) type interactions to intermolecular conjugation is significant than the former and hence to NLO property [20]. The reason is that the benzene rings are the reservoirs of charges and the involvement of these benzene rings in the hydrogen bond interactions lead to the highest conjugation in the exited state. The contribution to the crystal conjugation is still higher in the case of crystals structure showing $\pi \ldots \pi$ type interactions. Stronger the $\pi \ldots \pi$ and $\mathrm{C}-\mathrm{H} \ldots . \pi$ interactions more effecttive will be the contribution to the macroscopic NLO response. The MMONS show very high SHG due to the presence of strong $\pi \ldots \pi$ stacking interactions in the crystal structure [21]. In synthesized chalcone derivatives the D-H... $\mathrm{X}$ (where $\mathrm{X}=\mathrm{O}, \pi, \mathrm{Cl}, \mathrm{Br}$ ) and $\pi \ldots \pi$ type interactions are present (Table 2) [12-16]. In E3BC and EBC crystal structures $\mathrm{C}-\mathrm{HO}$ interaction stabilizes the packing and link the molecules in zigzag head-to-tail fashion in the crystal structures which help to establish a high SHG efficiency (11 and 14 times higher than urea, respectively) in these crystals $[15,16]$. In $3 \mathrm{MMC}$, both $\mathrm{C}-\mathrm{H} \ldots \mathrm{O}$ and $\mathrm{C}-\mathrm{H} . . . \pi$ interactions contribute to the macroscopic NLO response [13]. Among the compounds studied, EBC shows high SHG efficiency value compared with E3BC. The $\mathrm{Br}$ and $\mathrm{OC}_{2} \mathrm{H}_{5}$ are electron donating groups. Both chalcones can be considered as effective D-A-D (donor-acceptor-donor) type of molecule. In the case of D-A-D type of molecules charge transfer takes place through donor to acceptor. E3BC shows less value of SHG when compared with EBC molecules. Here, in this molecules $\mathrm{Br}$ is present at the meta position on the aromatic ring and the length of the charge transfer axis is less compared to other two molecules. It was observed that as the length of the charge transfer axis contributes to nonlinearity [22]. The dihedral angle between aromatic rings is $8.51(19)^{\circ}$, and $10.09(11)^{\circ}$ respectively for $\mathrm{EBC}$ and $\mathrm{E} 3 \mathrm{BC}$. The large dihedral angle of E3BC causes less efficient charge transfer through its backbone than compared with EBC and show less nonlinearity.

\subsection{UV-Vis-NIR Absorption}

$\mathrm{UV}$-Vis spectroscopy is the measurement of the attenuation of the light beam after it passes through a sample or after reflection from a sample surface. The UV-Vis spectrum gives information about the useful range of wavelength in which the NLO materials can be operational. We measured the absorption in the range $300-1100 \mathrm{~nm}$ to check the absorption of the fundamental Nd: YAG laser beam $(\lambda=1064 \mathrm{~nm})$ and second harmonic $(\lambda=1064$ $\mathrm{nm})$ in the synthesized materials. The electronic absorption spectrum of all the five chalcones show intense, broad bands in the visible region corresponding to intra-molecular charge-transfer (ICT) excitations from the electron donors to the acceptors (Table 2, Figure 3). The absorbance is not registered in the wavelength range starting from $430 \mathrm{~nm}$ to $1100 \mathrm{~nm}$. The nearly sharp rise in absorptions suggests nearly similar distribution of energies among all molecules of the chalcones. The peak absorption of the curves is mainly due to $\mathrm{n} \rightarrow \pi^{*}, \pi \rightarrow \pi^{*}$ transition and also due to the excitation of $\mathrm{C}=\mathrm{O}$ group of the molecule. The observed absorption maxima are in the UV region thus circumventing the nonlinear-transparency-tradeoff problem. In all materials, the $\lambda$ cut-off for absorption is well below $532 \mathrm{~nm}$, the wavelength of SHG corresponding to the $1064 \mathrm{~nm}$ fundamental beam. The molecules can be considered for device application in their region of transmission.

\subsection{Thermal Analysis}

Figure 4 shows the thermogram for DTA and TGA of five SHG chalcones. The DTA curves show a major exhothermic peak, which corresponds to the melting point of the respective compounds, after which the compounds decomposes into a sticky viscous substance. At higher temperatures, this decomposition process continues with the removal of almost the entire compound as gaseous products. The sharpness of the peaks demonstrated good crystallinity and purity of the sample. The TG curve of MCC, ECC, EBC adn E3BC sample indicate that the samples were stable up to $200^{\circ} \mathrm{C}, 250^{\circ} \mathrm{C}, 275^{\circ} \mathrm{C}$ and $280^{\circ} \mathrm{C}$. The exothermic peak of EBC and E3BC of DTA at $343.26^{\circ} \mathrm{C}$ and $343.16^{\circ} \mathrm{C}$ corresponding to the weight loss in the TG curve, indicated that the weight loss was due the degradation and evaporation of the samples. Melting points of all the chalcones determined by the 


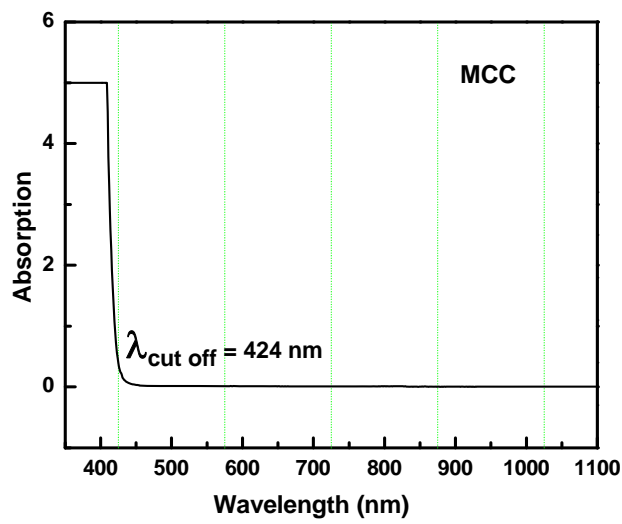

(a)

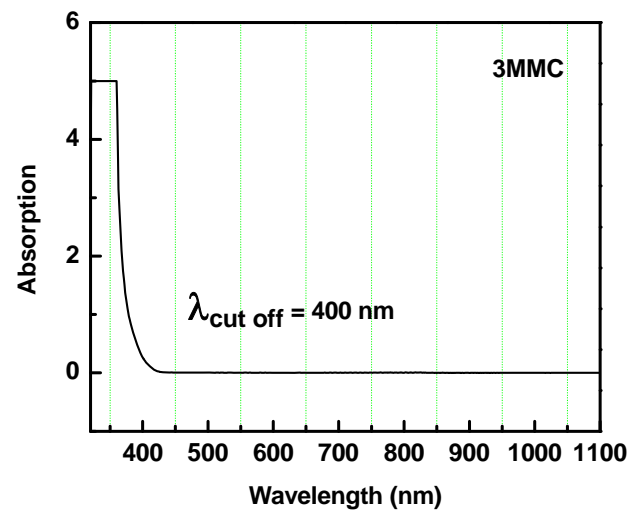

(b)

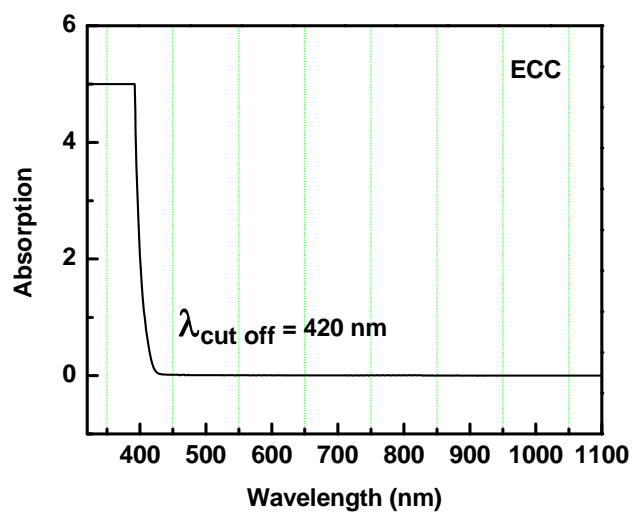

(c)

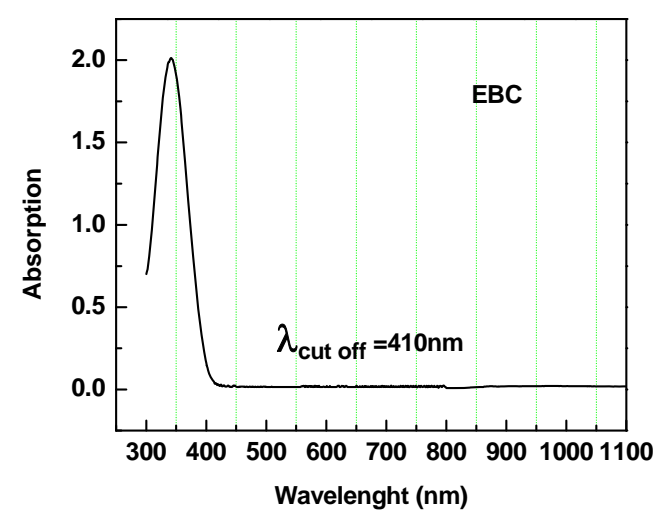

(d)

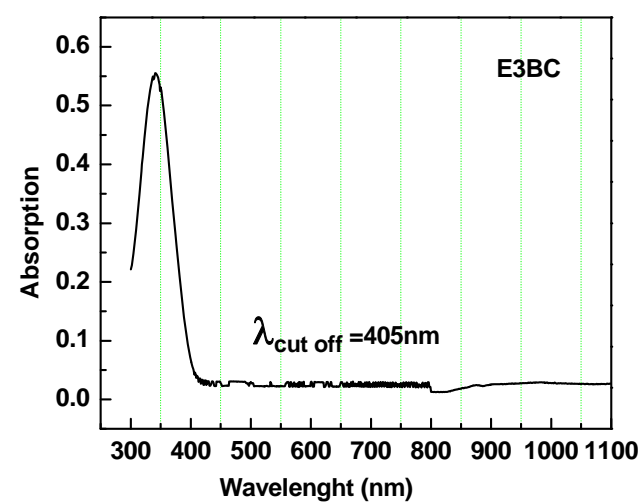

(e)

Figure 3. UV-Vis NIR absorption spectra of (a): MCC; (b): 3MMC; (c): ECC; (d): EBC; (e): E3BC.

open capillary method are same as measured by thermal analysis. The EBC has a quite high melting point of $128.08^{\circ} \mathrm{C}$.

\subsection{Powder X-Ray Diffraction}

Using Bruker D8 Advance X-ray diffractometer $(\lambda=1.54$ $\AA, \mathrm{CuK} \alpha$ ), diffraction pattern was recorded for the powdered MCC sample in the range of 10 to $45^{\circ}$ to identify the prominent plane which is required for high resolution diffraction study. X-ray powder diffraction pattern of MCC crystal is shown in Figure 5. The lattice paprameters of MCC calculated form the powder X-ray diffraction pattern are agrees with single crystal data (Table 2). The sharpness of the peaks shows good degree of crystallinity. $\mathrm{X}$-ray diffraction pattern has highest intensity corresponding to (220) plane.

\subsection{High-Resolution $X-$ Ray Diffraction (HRXRD) Analysis}

Figure 6 shows the high-resolution diffraction curve (DC) recorded for MCC specimen crystal using (220) diffracting planes in symmetrical Bragg geometry by employing the multicrystal X-ray diffractometer with $\mathrm{MoK} \alpha_{1}$ radiation. As seen in the figure, the curve is not having a single diffraction peak. The solid line, which follows well with the experimental points (filled circles), is the convoluted curve of two peaks using the Gaussian fit. The additional peak depicts an internal structural very low angle (tilt angle $\leq 1$ arc min) boundary [23] whose tilt angle (misorientation angle between the two crystalline regions on both sides of the structural grain boundary) is 43 arc sec from its adjoining region. The FWHM (full width at half maximum) of the main peak and the very low angle boundary are respectively 32 and 45 arc sec. Though the specimen contains a low angle boundary, the relatively low angular spread of around 200 arc sec of the diffraction curve and the low FWHM values show that 


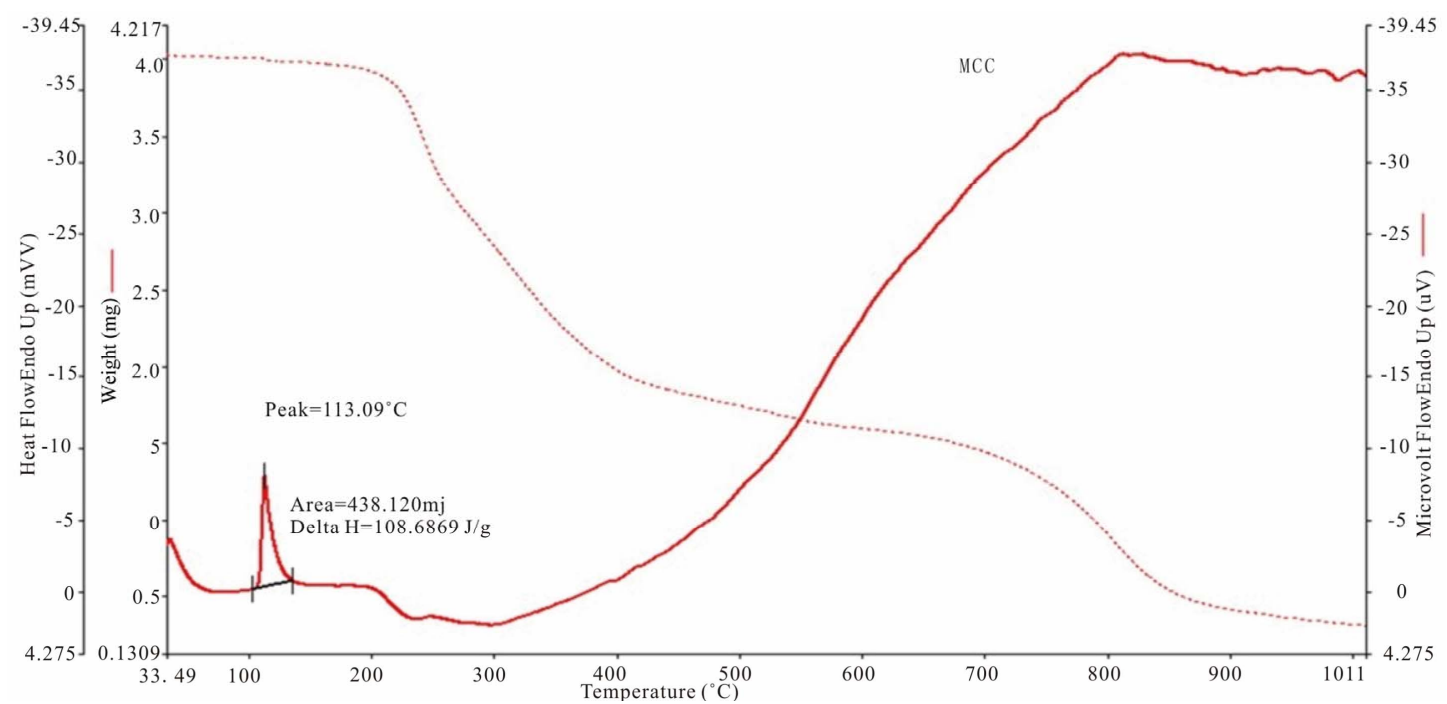

(a)

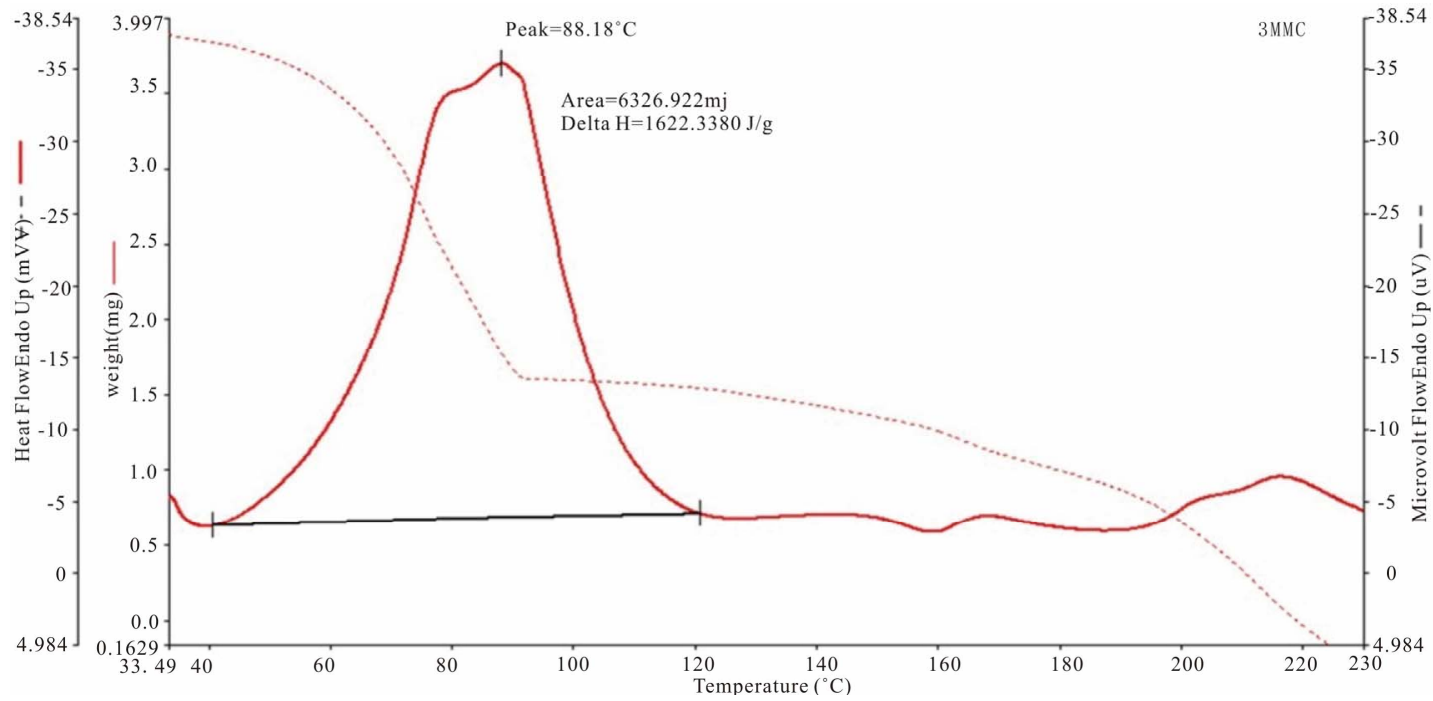

(b)

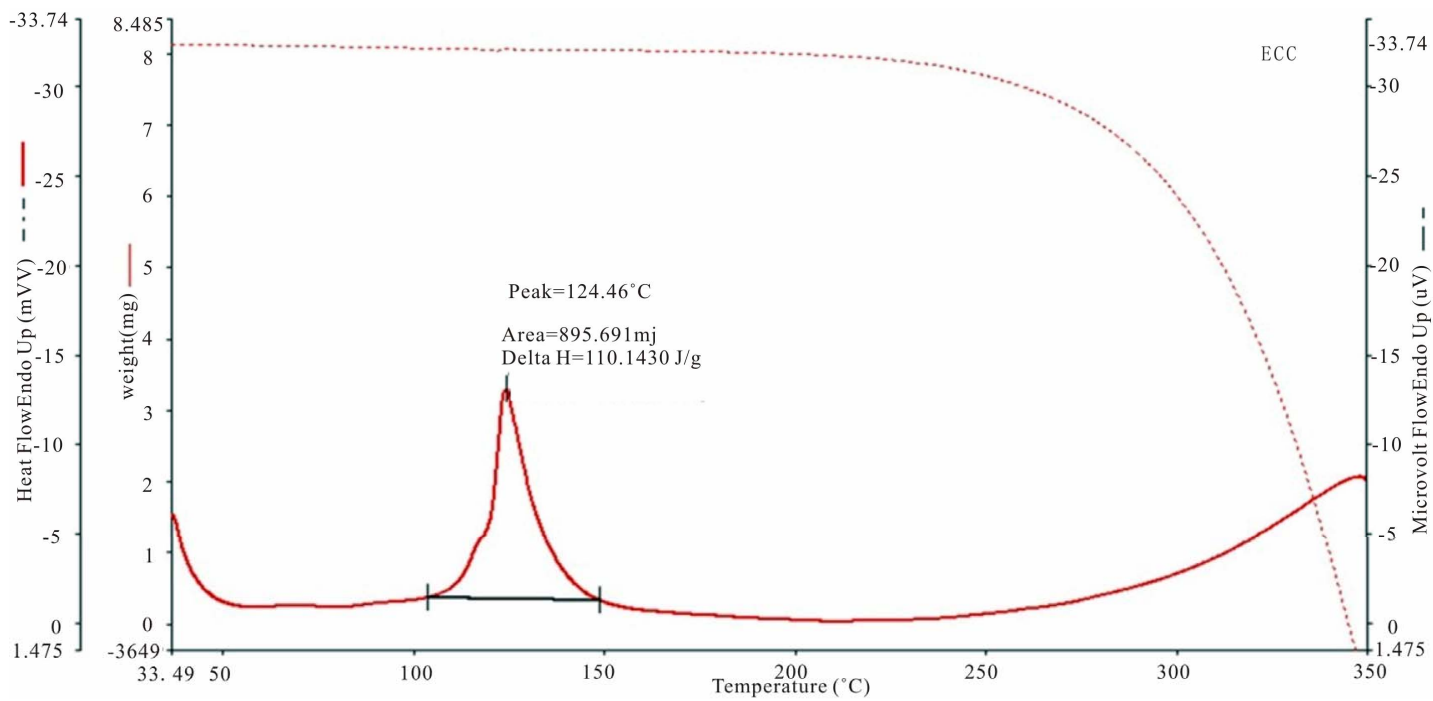

(c) 


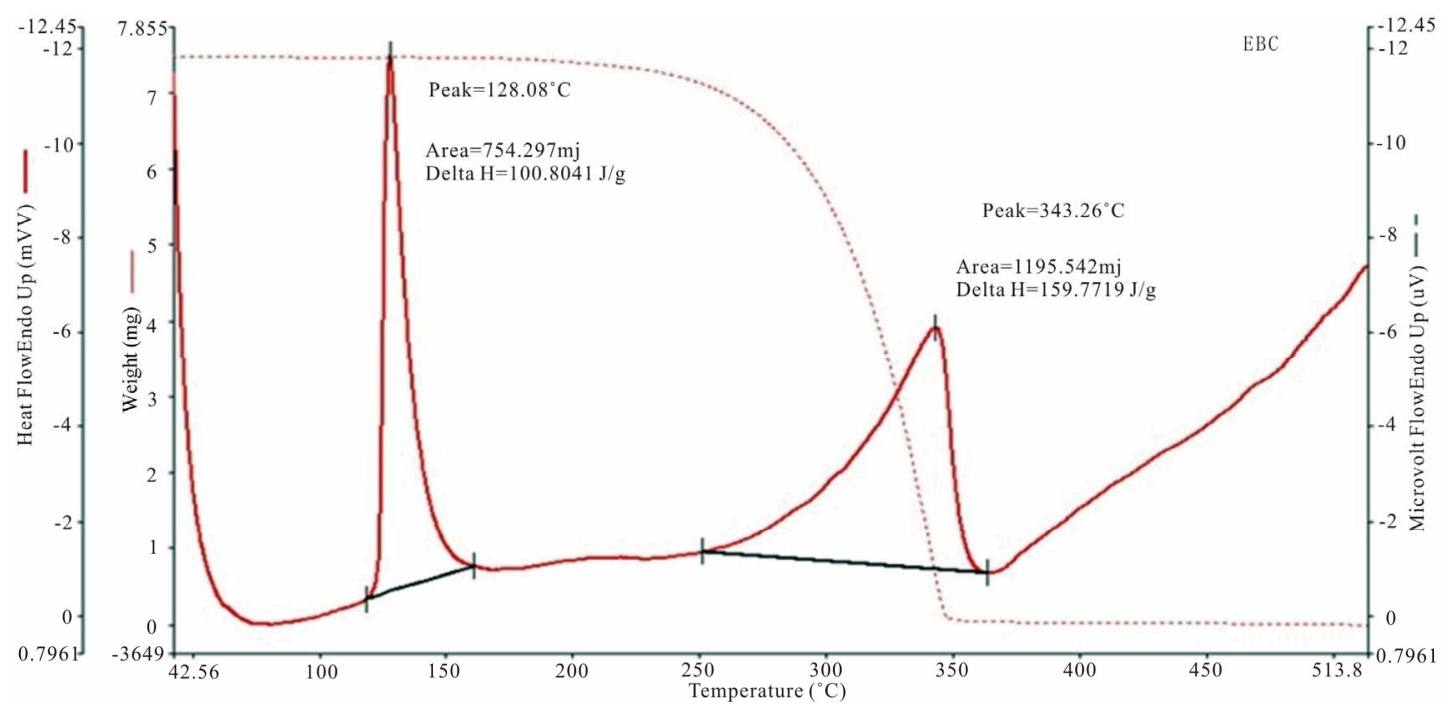

(d)

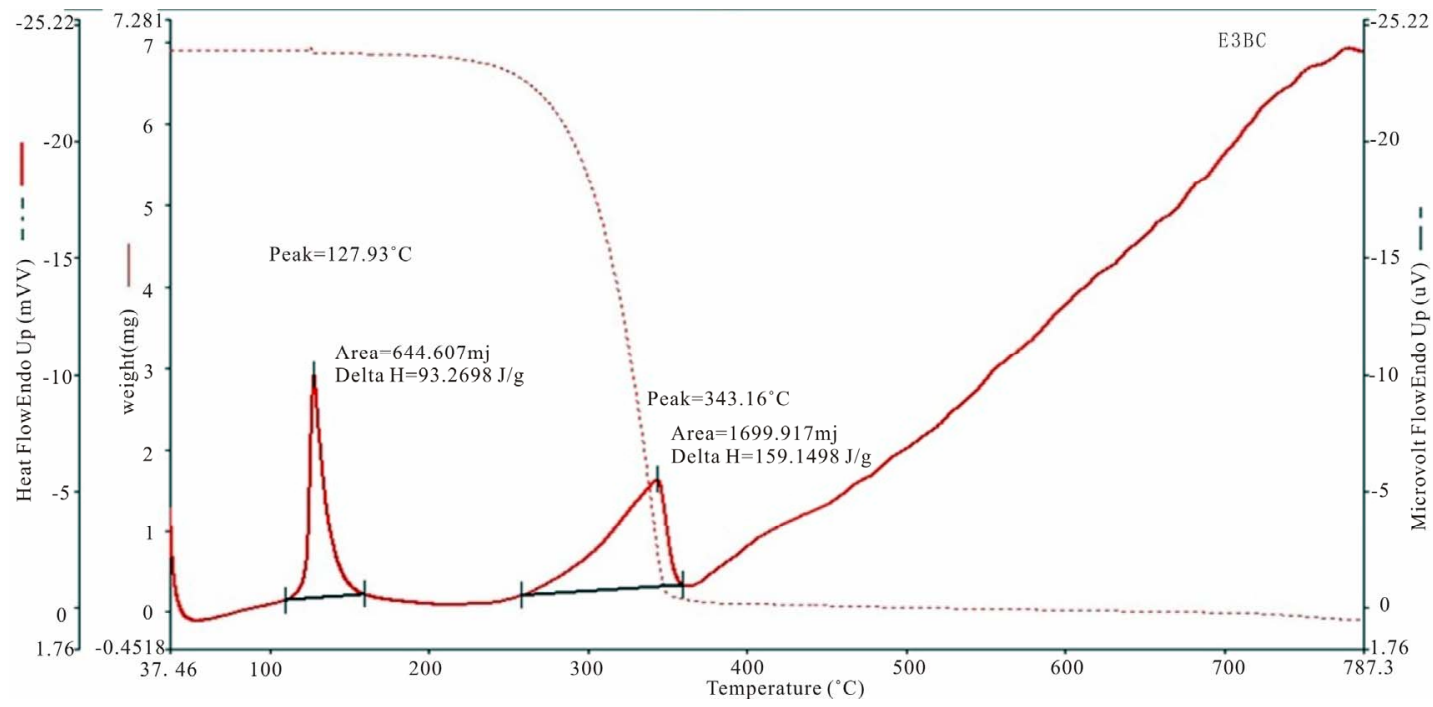

(e)

Figure 4. TGA and DTA curves of (a): MCC; (b): 3MMC; (c): ECC; (d): EBC; (e): E3BC.

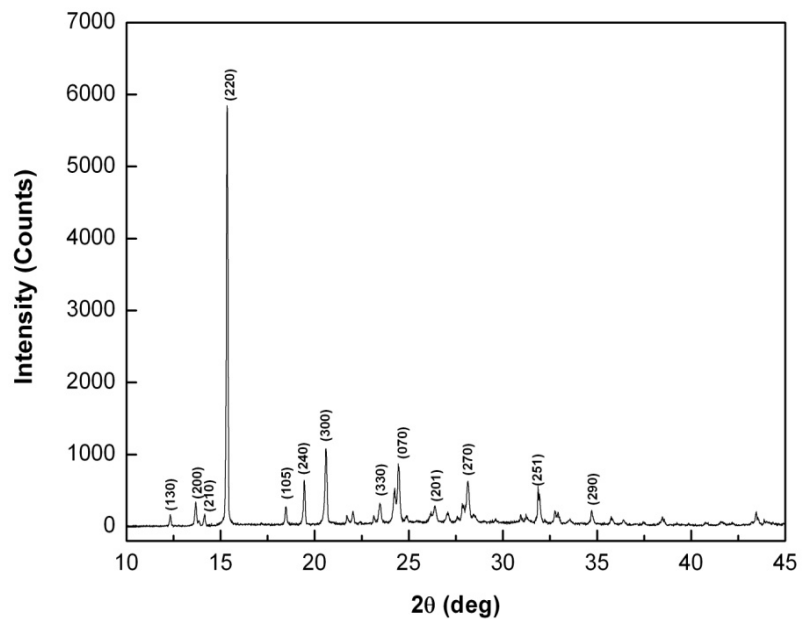

Figure 5. X-ray powder diffraction pattern of MCC. the crystalline perfection is reasonably good. The entrapment of impurities or solvent molecules could be responsible for the formation of these grain boundaries, which may be segregated at the boundaries during the growth process. It may be mentioned here that such a low angle boundary could be detected with well-resolved peak in the diffraction curve only because of the highresolution of the multicrystal X-ray diffractometer used in the present studies. The influence of such minute defects on the NLO properties is very insignificant. However, a quantitative analysis of such unavoidable defects is of great importance, particularly in case of phase matching applications.

\section{Conclusion}

Five new second order nonlinear optical chalcone deriva- 


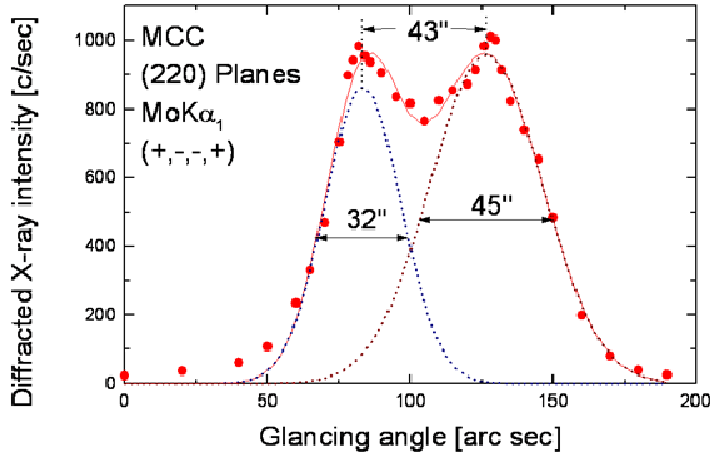

Figure 6. Diffraction curve recorded for MCC single crystal for (220) diffracting planes by employing the multicrystal $\mathrm{X}$-ray diffractometer with $\mathrm{MoK} \alpha_{1}$ radiation.

tives have been synthesized and characterized. The powder second harmonic generation (SHG) intensity of all these molecules is much greater than that of urea. Among the five chalcones, EBC is found to possess an efficiency of 14 times that of urea under the same conditions. The SHG efficiencies of these chalcones in the powdered state are discussed in terms of their arrangements in the unit cell. The materials have sufficient transmission in the entire visible and IR region and have better thermal stability. The HRXRD spectrum of MCC crystal shows the reasonably good crystalline nature. The results illustrate that all the chalcones are good NLO materials for second harmonic generation. In any event, donor-acceptor substituted chalcones seem appropriate for exploring new NLO organic naterials.

\section{Acknowledgements}

PSP thanks Dr. B. S. Anami, Principal, K. L. E. Institute of Technology, Hubli for his constant encouragement and facilitating my research work by way of providing the required infrastructure.

\section{REFERENCES}

[1] P. N. Prasad and D. J. Williams, "Introduction to Nonlinear Optical Effects in Organic Molecules and Polymers," New York, Wiley, 1991.

[2] D. S. Chemla and J. Zyss, "Nonlinear Optical Properties of Organic Molecules and Crystals," Orlando, Academic Press, 1987.

[3] R. L. Sutherland, D. G. McLean and S. Kirkpatrick, "Handbook of Nonlinear Optics," 2nd Edition, Marcel Dekker, New York, 2003. doi:10.1201/9780203912539

[4] P. S. Patil, S. M. Dharmaprakash, H.-K. Fun and M. S. Karthikeyan, "Synthesis, Growth, and Characterization of 4-OCH3-40-Nitrochalcone Single Crystal: A Potential NLO Material," Journal of Crystal Growth, Vol. 297, No. 1, 2006, pp. 111-116. doi:10.1016/j.jcrysgro.2006.09.017

[5] B. Gu, W. Ji, P. S. Patil and S. M. Dharmaprakash, "Ul- trafast Optical Nonlinearities and Figures of Merit in Acceptor-Substituted 3,4,5-Trimethoxy Chalcone Derivatives: Structure-Property Relationships," Journal of Applied Physics, Vol. 103, No. 10, 2008, pp. Article ID: 103511. doi:10.1063/1.2924419

[6] B. Gu, W. Ji, X.-Q. Huang, P. S. Patil and S. M. Dharmaprakash, "Nonlinear Optical Properties of 2,4,5-Trimethoxy-4'-Nitrochalcone: Observation of Two-Photon-Induced Excited-State Nonlinearities," Optics Express, Vol. 17, No. 2, 2009, pp. 1126-1135. doi:10.1364/OE.17.001126

[7] J. W. Chen, X. Q. Wang, Q. Ren, P. S. Patil, T. B. Li, H. L. Yang, J. N. Zhang, G. C. Li and L. Y. Zhu, "Investigation of Third-Order Nonlinear Optical Properties of NNDCDoped PMMA Thin Films by Z-Scan Technique," Applied Physics A, Vol. 105, No. 3 2011, pp. 723-731. doi:10.1007/s00339-011-6628-1

[8] E. P. Kohler and H. M. Chadwell, "Organic Syntheses," Collective, Vol. 5, 1941, p. 78.

[9] S. K. Kurtz and T. T. Perry, "A Powder Technique for the Evaluation of Nonlinear Optical Materials," Journal of Applied Physics, Vol. 39, No. 8, 1968, pp. 3798-3814. doi:10.1063/1.1656857

[10] K. Lal and G. Bhagavannarayana, "A High-Resolution Diffuse X-Ray Scattering Study of Defects in Dislocation-Free Silicon Crystals Grown by the Float-Zone Method and Comparison with Czochralski-Grown Crystals," Journal of Applied Crystallography, Vol. 22, No. 3, 1989, pp. 209-215. doi:10.1107/S0021889888014062

[11] G. Bhagavannarayana, S. Parthiban and S. Meenakshisundaram, "Enhancement of Crystalline Perfection by Organic Dopants in ZTS, ADP and KHP Crystals as Investigated by High-Resolution XRD and SEM," Journal of Applied Crystallography, Vol. 39, No. 6, 2006, pp. 784-790. doi:10.1107/S0021889806033139

[12] W. T. A. Harrison, H. S. Yathirajan, B. K. Sarojini, B. Narayana and J. Indira, "1-(4-Chlorophenyl)-3-(4-methoxyphenyl)prop-2-en-1-one," Acta Crystallographica Section E, Vol. E62, No. 4, 2006, pp. o1647-o1649. doi:10.1107/S1600536806010865

[13] P. S. Patil, J. B. J., Teh, H.-K. Fun, H. B. Ramesh Babu, Ibrahim Abdul Razak and S. M. Dharmaprakash, "3-(3Methoxyphenyl)-1-(4-methoxyphenyl)prop-2-en-1-one," Acta Crystallographica Section E, Vol. E63, No. 4, 2007, pp. o1895-o1896. doi:10.1107/S160053680701255X

[14] P. S. Patil, H.-K. Fun, S. Chantrapromma and S. M. Dharmaprakash, "1-(4-Chlorophenyl)-3-(4-ethoxy phenyl) prop-2-en-1-one," Acta Crystallographica Section E, Vol. 63, No. 5, 2007, pp. o2497-o2498. doi:10.1107/S1600536807017394

[15] H.-K. Fun, P. S. Patil, S. M. Dharmaprakash and S. Chantrapromma, "1-(4-Bromophenyl)-3-(4-ethoxyphenyl) prop-2-en-1-one," Acta Crystallographica Section E, Vol. E64, No. 8, 2008, pp. o1540-o1541. doi:10.1107/S1600536808021776

[16] H.-K. Fun, S. Chantrapromma, P. S. Patil and S. M. Dharmaprakash, "(E)-1-(3-Bromophenyl)-3-(4-ethoxyphenyl)prop-2-en-1-one," Acta Crystallographica Section E, Vol. E64, No. 7, 2008, pp. o1356-o1357. 
doi:10.1107/S1600536808018850

[17] G. R. Desiraju and T. Steiner, "The Weak Hydrogen Band in Structural Chemistry and Biology," Oxford University Press, Oxford, 1999.

[18] K. M. Sureshan, T. Uchimaru, Y. Yao, Y. Watanabe, "Strength from Weakness: CH... $\pi$ Stabilized Conformational Tuning of Benzyl Ethers and a Consequent CoOperative Edge-to-Face CH Network," CrystEngComm, Vol. 10, No, 5, 2008, pp. 493-496. doi: $10.1039 / \mathrm{b} 718099 \mathrm{c}$

[19] R. W. Munn and C. N. Ioronside, "Principles and Applications of Nonlinear Optical Materials," Chapman and Hell, London, 1993. doi:10.1007/978-94-011-2158-3

[20] J. M. Cole, J. A. K. Howard and G. J. MCIntyre, "Influence of Hydrogen Bonding on the Second Harmonic Generation Effect: Neutron Diffraction Study of 4-Nitro-4'Methylbenzylidene Aniline," Acta Crystallographica Section B, Vol. B57, No. 3, 2001, pp. 410-414. doi:10.1107/S0108768101002154
[21] W. Tam, B. Guerin, J. C. Calabrese and S. H. Stevenson, "3-Methyl-4-methoxy-4'-nitrostilbene (MMONS): Crystal Structure of a Highly Efficient Material for SecondHarmonic Generation," Chemical Physics Letters, Vol. 154, No. 2, 1989, pp. 93-96. doi:10.1016/S0009-2614(89)87265-3

[22] P. Poornesh, K. Ravi, G. Umesh, P. K. Hegde, M. G. Manjunatha, K. B. Manjunatha and A. V. Adhikari, "3,3'Benzene1,4-diylbis[1-(substituted)phenylprop-2-en-1-one] Derivatives: A New Class of Materials for Third-Order Nonlinear Optical Applications," Optics Communications, Vol. 283, No.7, 2010, pp. 1519-1527. doi:10.1016/j.optcom.2009.12.015

[23] G. Bhagavannarayana, R. V. Ananthamurthy, G. C. Budakoti, B. Kumar and K. S. Bartwal, "A Study of the Effect of Annealing on Fe-Doped $\mathrm{LiNbO}_{3}$ by HRXRD, XRT and FT-IR," Journal of Applied Crystallography, Vol. 38, No. 3, 2005, pp. 768-771. doi:10.1107/S0021889805023745 